\title{
Bone Overgrowth after Fracture of the Femoral Shaft in Children
}

\author{
SM Yong, MS (Ortho)*, A Saw, FRCS**, S Sengupta, FRCS**, AM Bulgiba, PhD*** \\ *Department of Orthopaedics and Traumatology, Hospital Selayang, Selangor, Malaysia \\ **Department of Orthopaedic Surgery, University Malaya Medical Centre, Kuala Lumpur, Malaysia \\ ${ }^{* * *}$ Department of Social and Preventive Medicine, University Malaya Medical Centre, Kuala Lumpur, Malaysia
}

\begin{abstract}
Forty children treated non-operatively for fractures of the femoral shaft were reviewed with regard to differences in limb length after treatment. Follow up duration ranged from two to seven years. The average femoral overgrowth was $0.85 \mathrm{~cm}$ (range $0-2.5 \mathrm{~cm}$ ) and was influenced by age at the time of fracture. We were not able to find any association between the quantity of overgrowth and race, gender, level or configuration of the fracture.
\end{abstract}

Key Words:

Children, Femoral shaft fracture, Overgrowth

\section{INTRODUCTION}

There are many published studies regarding overgrowth of the femur after fracture in a growing child. In 1921, Truesdell $^{1}$ was the first to report on post traumatic increase in growth. This phenomenon of overgrowth had been attributed by Speed $^{2}$ to a compensatory mechanism. Others regarded the increase to be due to hyperaemia associated with the healing process ${ }^{3}$.

It is important to recognise the factors that influence overgrowth, so that overriding of bone fragments can be adjusted in such a way as to minimize the final leg length discrepancy. Various authors have recommended differing amounts of overlap ranging from $1.5 \mathrm{~cm}$ to $3.0 \mathrm{~cm}^{4,5,6,7}$. Most studies published to date are based on Western populations. In 1989 Stephens, Hsu and Leung ${ }^{8}$ reviewed a series of 30 skeletally mature patients in Hong Kong after isolated femoral fractures in childhood (age range at time of fracture - 7 - 13 y), however, children below the age of seven were not included in this study. We therefore conducted a retrospective study on children with femoral shaft fractures treated at our institution to investigate the degree of overgrowth and have attempted to correlate clinical factors that may influence the outcome with such overgrowth.

\section{MATERIALS AND METHODS}

We retrospectively reviewed charts of all children between the ages of 0 to 12 years who presented at our hospital with unilateral femoral shaft fractures from January 1992 to October 1997. Patients with less than 2 years of follow up, pathological fractures, bilateral fractures and fractures treated with internal fixation were excluded.

Treatment of the patients was age dependent. Bryant's traction was used for children under the age of two or less than $6.8 \mathrm{Kg}$. The traction would be applied on both lower limbs for about 3 weeks, with the child's buttocks lifted just off the surface of the mattress. Hip spica was applied for an additional 3 weeks. For older children, skin traction would be applied for 3 weeks using a Thomas splint. Weights were adjusted based on radiographs, so that the fragments overlapped by about $1.0 \mathrm{~cm}$. Hip spica would then be applied for an additional 3 to 5 weeks.

Radiographs taken at the time of admission till callus formation were reviewed. We assumed that limb lengths were equal prior to fracture; therefore the amount of overlap would represent the initial limb length discrepancy. Magnification factor was taken into consideration. Final limb length discrepancy was evaluated clinically, with the patient in a supine position and the pelvis squared. One researcher conducted all clinical evaluations to prevent discrepancy due to different evaluators. Distance between the distal point of the anterior superior iliac spine (ASIS) to the tip of the medial malleolus was measured. The average of three measurements was used as the recorded discrepancy. Overgrowth was determined by subtracting the final limb length discrepancy from the initial limb length discrepancy. Range of motion of the hips and knees were also assessed. Patients were asked about any limitations in sports or daily activities. Complications such as postural scoliosis due to limb length discrepancy and abnormal gait were also investigated. 
Results were analysed using the SPSS (Statistical Package for the Social Sciences) Version 11 for Windows. Data cleaning and pre-processing was performed before analysis. Distributions were examined and variances were tested for homogeneity before statistical testing. The t-test and oneway ANOVA (with Scheffe's post-hoc test) were used to compare means between groups. Prior to utilizing the $t$ test or ANOVA, normality assumptions were assessed using the Kolmogorov-Smirnov test and homogeneity of variances were tested using the Levene's test. All statistical tests were carried out using a significant level of 0.05 and $95 \%$ confidence intervals were calculated for all factors under study.

\section{RESULTS}

A total of 58 patients were admitted for femoral fracture during this period of study. Twelve patients had their subsequent follow up in other hospitals. There were two pathological fractures, and another two were treated with fixation. We were not able to trace the folders and initial radiographs for 2 other patients. Families for the remaining 40 patients were willing to return for clinical evaluation. The mean follow-up period was 54.9 months (range: 27 to 81 months). All patients included in this study had at least 24 months of follow-up. Mean overgrowth for the study sample was $0.85 \mathrm{~cm}$ (range from $0-2.5 \mathrm{~cm}$ )

\section{Gender and overgrowth}

There were 29 males and 11 females included in the current study. Mean overgrowth of the femur in male patients was $0.90 \mathrm{~cm}$ whereas that of female patients was $0.71 \mathrm{~cm}$. The mean difference between the males and females was $0.18 \mathrm{~cm}$ but there was no statistically significant difference between the two groups (Table I).

\section{Race and overgrowth}

Twenty-two (55\%) of the children were Malaysian, ten (25\%) were Chinese and eight $(20 \%)$ were Indian. Mean overgrowth in Malays was $0.75 \mathrm{~cm}$; Chinese, $0.85 \mathrm{~cm}$ and Indian, $1.1 \mathrm{~cm}$. There were no statistically significant differences in mean overgrowth between the three groups (Table I).

\section{Age groups and overgrowth}

The children were divided into three different age groups; twelve $(30 \%)$ were $<2$ years; seventeen $(42.5 \%)$ were between 2 to 7 years and eleven (27.5\%) were 7 to 12 years of age. The mean age of all children was 4 years and 6 months. Mean overgrowth of the femur in children below the age of two was $0.36 \mathrm{~cm}$. Older children between the ages of 2 to 7 had a mean overgrowth of $0.95 \mathrm{~cm}$ and those between the ages of 7 to 12 had a mean overgrowth of $1.22 \mathrm{~cm}$.

The mean difference in overgrowth between $<2$ years and the 2 to 7 years age group was statistically significant $(\mathrm{p}<$
0.026). The difference between the less than 2 years and the 7 to 12 age group was also found to be statistically significant $(\mathrm{p}<0.003)$. However, there was no statistically significant difference between the 2 to 7 and the 7 to 12 age groups (Table I).

\section{Level of fracture and overgrowth}

Thirteen $(33 \%)$ of the fractures were in the upper third of the femur; twenty-three $(57 \%)$ were in the middle and four $(10 \%)$ were in the lower third. Mean overgrowth of fractures in the upper third group was $0.94 \mathrm{~cm}$; for the middle third the mean was $0.77 \mathrm{~cm}$ and lower third mean was $1.00 \mathrm{~cm}$. There were no statistically significant differences found between the three groups (Table I).

\section{Pattern of fracture and overgrowth}

The mean overgrowth for transverse fractures (22 cases) was $0.86 \mathrm{~cm}$; oblique fracture (9 cases) $0.87 \mathrm{~cm}$ and spiral fracture ( 9 cases) $0.78 \mathrm{~cm}$. There were no statistically significant differences found between the three groups (Table I).

\section{Correlation between initial shortening and subsequent overgrowth}

Based on the Pearson correlation test, there was a positive correlation between initial shortening and subsequent overgrowth of the fractured limb. The correlation coefficient was $0.74(p<0.01)$. However, it was not a perfect correlation as some cases did not show any overgrowth.

\section{Final limb length}

In this study, all but 5 patients had overgrowth. However, not all of those patients with overgrowth had equal limb length at follow-up, although, all showed reduction of the initial discrepancy. 22 of the 40 patients achieved equal limb length, 16 had shortening and 2 showed increased length on the fractured side. Ten patients had shortening of 0.5 to 1.0 $\mathrm{cm}$; five had 1.0 to $1.5 \mathrm{~cm}$ shortening and one had shortening of $2.0 \mathrm{~cm}$. The two patients who showed increased length had $0.5 \mathrm{~cm}$ of lengthening

\section{Complications}

There was one case of postural scoliosis which was correctable with a raised shoe in a child with $2.0 \mathrm{~cm}$ shortening. All other patients were able to participate in sports and normal activities. Clinically, all patients had full range of hip and knee movement.

\section{DISCUSSION}

In 1923, Burdick and Siris ${ }^{9}$ reported on a large study of fractures of the shaft of femur in children. Of these, $118 \mathrm{had}$ a shortening of $0.5-3 \mathrm{~cm}$ at discharge. Within 3 years, 53 of those children had bone length equality while others had less discrepancy. The authors drew a practical conclusion that slight shortening in fractures of this nature need not be 
Table I: Mean overgrowth and predictors

\begin{tabular}{|c|c|c|}
\hline Factor & Number & Mean in $\mathrm{cm}(95 \% \mathrm{Cl})$ \\
\hline \multicolumn{3}{|l|}{ Gender } \\
\hline Male & 29 & $0.90(0.64,1.15)$ \\
\hline Female & 11 & $0.71(0.33,1.08)$ \\
\hline \multicolumn{3}{|l|}{ Race } \\
\hline Malay & 22 & $0.75(0.45,1.04)$ \\
\hline Chinese & 10 & $0.85(0.47,1.23)$ \\
\hline Indian & 8 & $1.11(0.57,1.65)$ \\
\hline \multicolumn{3}{|l|}{ Age group } \\
\hline $0-<2$ & 12 & $0.36(0.08,0.64)$ \\
\hline $2-<7$ & 17 & $0.95(0.68,1.21)$ \\
\hline $7-<12$ & 11 & $1.22(0.76,1.68)$ \\
\hline \multicolumn{3}{|l|}{ Level of fracture } \\
\hline Upper Third & 13 & $0.94(0.49,1.39)$ \\
\hline Middle Third & 23 & $0.77(0.53,1.00)$ \\
\hline Lower Third & 4 & $1.00(0,2.30)$ \\
\hline \multicolumn{3}{|l|}{ Pattern of fracture } \\
\hline Spiral & 9 & $0.78(0.45,1.10)$ \\
\hline Oblique & 9 & $0.87(0.49,1.24)$ \\
\hline Transverse & 22 & $0.86(0.52,1.20)$ \\
\hline
\end{tabular}

corrected. In the same year, Speed ${ }^{2}$ published an article in which he discussed overgrowth in relation to osteomyelitis, but in the introduction, he mentioned in passing that he had observed about 20 cases of so-called compensatory overgrowth as a result of fractures the femur. According to Blount ${ }^{10}$, open reductions of diaphyseal fractures were practically never indicated as they were associated with a risk of significant increase in growth. He recommended that the diaphyseal femur fractures in children be allowed to heal with a shortening of $1-2 \mathrm{~cm}$, which would likely be eliminated during the course of further growth. He found no relationship between the distance of the fracture from the growth plates and the degree of the overgrowth.

In this study, we found that the age of the patient at the time of the fracture influenced the final quantity of femoral overgrowth. There was significantly more overgrowth in the 2 to 7 and the 7 to 12 years age groups compared to the $0-2$ years age group. Literature searches regarding the influence of age on overgrowth were hampered by the different age distributions from study to study. Several authors found that overgrowth was related to age $\mathrm{s}^{5,11,12,13}$. Most expressed the opinion that overgrowth was greatest when the fracture occurred in children aged between 4 and 8 . Other authors found no statistically significant difference in overgrowth between different age groups ${ }^{14,15,16}$.

Similar to the findings of Shapiro ${ }^{15}$, we found that the gender of the child did not influence the amount of overgrowth. However, Clement and Colton ${ }^{3}$ found that the most important factor influencing overgrowth was gender. There was no statistical difference in the amount of femoral overgrowth based on the race of the patient.

We also found that overgrowth did not appear to be influenced by level of the femoral fracture, similar to findings reported by several other studies. ${ }^{1,15,16}$, whereas Staheli ${ }^{12}$ (1967) reported more overgrowth in proximal fractures. From our data, we did not find any difference in the amount of overgrowth between oblique, transverse and spiral fractures, unlike findings reported by Barford and Christensen ${ }^{5}$ (1958). In their follow-up study of 114 femurs, oblique and comminuted fractures were shown to produce more overgrowth.

\section{CONCLUSION}

Overgrowth after fracture of the femur in children is a universal phenomenon. A mean increase in length of 0.85 $\mathrm{cm}$ can be expected in the affected femur, although those below 2 years old have less potential for such overgrowth. Gender, race, level and pattern of fracture do not affect the quantity of overgrowth. Although a majority of patients end up with equal limb length, we expect all patients to achieve a reduction of the initial discrepancy in length; of those patients who do not show equal leg length at the last followup, most have slight shortening, while a smaller number will have slight lengthening. 
Bone Overgrowth after Fracture of the Femoral Shaft in Children

\section{REFERENCES}

1. Truesdell ED. Inequality of the lower extremities following fracture of the shaft of the femur in children. Ann Surg. 1921; 74(4): 498-500.

2. Speed K. Analysis of the results of treatment of fractures of the femoral diaphysis in children under twelve years of age. Surg Gynaecol. Obstet. 1921; 32: 527-34.

3. Clement DA, Colton CL. Overgrowth of the femur after fracture in childhood: an increase effect in boys. J Bone Joint Surg. 1986; 68B(4): 534-6.

4. Neer CS and Cadman EF. Treatment of fractures of the femoral shaft in children. J Am Med Assoc. 1957; 163(8): 634-7.

5. Barford B, Christensen J. Fractures of the femoral shaft in children with special reference to subsequent overgrowth. Acta Chir Scand. 1958-59; 116(3): 235-50.

6. Bathfield CA, Verfeld GA, Schepers A. Overgrowth following femoral fractures in children. J Bone Joint Surg. 1979; 61B: 2567.

7. Griffin PP, Anderson M, Green WT. Fractures of the shaft of femur in children. Orthop Clin North Am. 1972; 3(1): 213-24.

8. Stephens MM, Hsu LCS, Leong JCY. Leg length discrepancy after femoral shaft fractures in children: review after skeletal maturity. J Bone Joint Surg. 1989; 71B(4): 615-8.

9. Burdick CG, Siris IE. Fractures of the femur in children. Treatment and end results in 268 cases. Ann Surg. 1923; 77: 736.

10. Blount WP. Fractures in children. Baltimore, Williams and Wilkins, 1954.

11. Greville NR, Ivins JC. Fracture of the femur in children: an analysis of their effect on the subsequent length of both bones of the lower limb. Am J Surg. 1957; 93(3): 376-84.

12. Staheli LT. Femoral and tibial growth following femoral shaft fracture in childhood. Clin Orthop 1967; 55: 159-63.

13. Kohan L, Cumming WJ. Femoral shaft fractures in children: the effect of initial shortening on subsequent limb overgrowth. Aust N.Z J Surg. 1982; 52(2): 141-4.

14. Viljanto J, Kiviluoto H, Paananen M. Remodelling after femoral shaft farctures in children. Acta Chir Scand. 1975; 141(5): 36065.

15. Shapiro F. Fractures of the femoral shaft in children: the overgrowth phenomenon. Acta Orthop Scand. 1981; 52(6): 649-55.

16. Edvardsen P, Syversen SM. Overgrowth of the femur after fracture of the shaft in childhood. J Bone Joint Surg. 1976; 58-B(3): 339-42. 